\title{
Upper Permian to Lower Triassic Carbon Isotope Record in the Oman and Zagros Mountains: An Overview From the Shallow Platform to the Basin
}

\author{
Sylvain Richoz (Commission for the Palaeontological and Stratigraphical Research of \\ Austria (CPSA) and Austrian Academy of Sciences c/o Institute of Earth Sciences, University \\ of Graz<sylvain.richoz@uni-graz.at>), Aymon Baud (Lausanne, Switzerland), Leopold \\ Krystyn (Vienna University, Austria) and Micha Horacek (Austrian Institute of Technology)
}

The Oman Mountains as well as the Zagros Mountains expose a segment of Neo-Tethyan southern margin. We will review the $\delta^{13} \mathrm{C}$ and $\delta^{18} \mathrm{O}$ isotope curves in various sections from shallow- to deep-water facies zones for the Upper Permian-Lower Triassic carbonate sequences from Oman and show some preliminary results from Zagros. The shallow-water environment was measured in the Al Jabal al-Akhdar Mountains (Wadi Sathan section), the Saih Hatat (Wadi Sawat) and the Musandam (Wadi Shahha), and the slope carbonates of the platform margin in the Sumeini area (Wadi Maqam). Deep-water deposits from the basinal sector of the margin were studied in the Hawasina Nappes (Wadi Wasit South, Wadi Musjah and Buday'ah) and the Bata'in complex (Sal). Drowned carbonate platform (Oman Exotics) and tilted blocs of the platform have also been studied (Ba'id and Wadi Wasit block).

Not all the sections span the Upper Permian until the Spathian without gap and/or sufficient biostratigraphic constraints but we could reconstruct a well-founded curve for the three paleosettings and we can use it as an efficient correlation tool for the Khuff and Sudair formations or equivalent.

Wordian to Wuchiapingian carbonates have high $\delta^{13} \mathrm{C}$ values between $+3 \%$ and $+6.6 \%$. The Changhsingian is missing or not proven in many sections except at Maqam and Wadi Sahtan, where the main negative carbon-isotope excursion typical for the Permian/Triassic Boundary interval is present. The Griesbachian sediments display negative values, constantly increasing upwards. In Wadi Wasit block, this increase is simultaneous with the increase in biodiversity. In many other sections worldwide the upper Griesbachian units show a negative excursion, which is here present only in Wadi Sahtan. In Wadi Wasit block this period is probably absent or condensed. In other sections a Dienerian megabreccia evidences erosion of upper Griesbachian sediments.

The Dienerian sediments, when present, are thin and show increasing carbon-isotope values. The upper Dienerian ( $N$. cristigalli Zone) shows a very short distinct negative excursion of $1.5 \%$ to $4 \%$, more pronounced in the basinal sediments. This short excursion is followed by a strong double positive peak of $1.9 \%$ to $7.5 \%$ amplitude. These peaks are again stronger in basinal sediments and less marked on the platform. Above very negative $\delta^{13} \mathrm{C}$ values last for most of the Smithian with values between $0.9 \%$ and $-2.5 \%$ in all the different paleo-settings, indicating increased ocean circulation. The Smithian/Spathian boundary, present in Wadi Sahtan, Wadi Maqam and Sal is marked by a short strong positive peak with amplitude up to $7.2 \%$ and, again, more pronounced in the basinal sediments.

In summary, the Wordian and Wuchiapingian give a consistent dataset, the Changhsingian and Griesbachian are poorly preserved, whereas during Dienerian to Spathian time, platform and basin are showing divergent amplitude in the carbon isotope signal. 


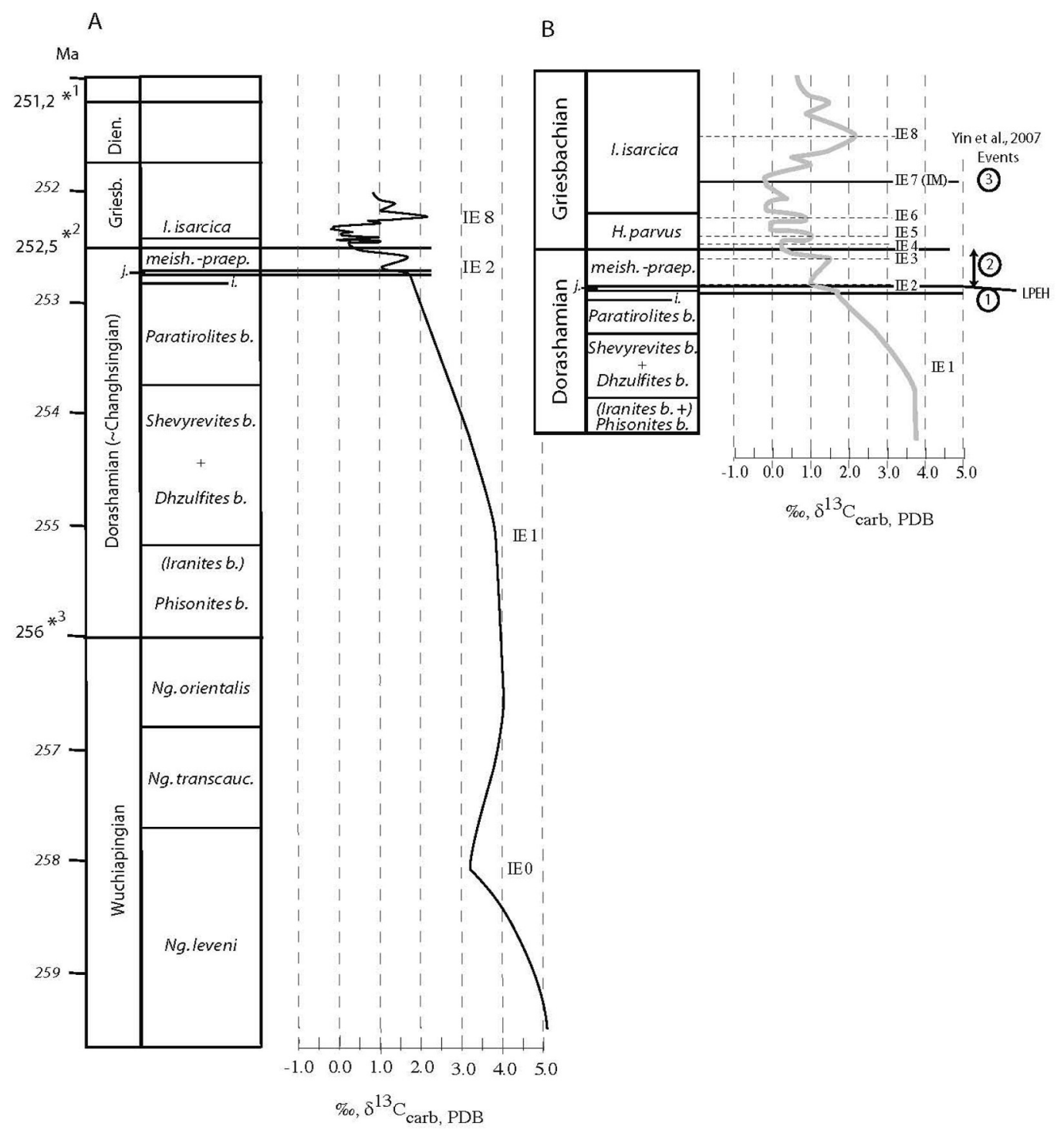

Proposed generalized isotopic curve for the Upper Permian and lowermost Triassic. In (A) the thickness of the zonation is interpolated in function of absolute age, *. In $\mathrm{B}$, the zonation is a function of the thickness of beds in Iran.

i. : iranica Zone;

j. : jolfensis Interval;

IE 0-8 : Isotope events. 